\title{
Pandemic (H1N1) 2009: assessing the response
}

\section{Donald E. Low MD, Allison McGeer MD}

Previously published at www.cmaj.ca

See also research article by Skowronski and colleagues, page 1851

In preparing for battle, I have always found that plans are useless, but planning is indispensable. - Dwight D. Eisenhower

$\mathrm{T}$ he debate about the management of pandemic (H1N1) 2009 is heating up as a number of government-appointed committees and private interest groups start to make their assessments available. ${ }^{1-8}$ On one hand is concern that the severity of the pandemic was overestimated and resources were wasted $;^{1,2}$ on the other hand are criticisms that a necessary immunization program was woefully inadequate and plagued by confusion. ${ }^{5}$

\section{Was the pandemic overhyped?}

A report published by the Council of Europe Directorate of Communication ${ }^{1}$ claims that the guidelines issued by the World Health Organization (WHO), European Union agencies and national governments led to "unjustified scares and fears about the health risks faced by the European public." An article $^{2}$ published in the $B M J$ alleged that some of the experts advising the $\mathrm{WHO}$ on the pandemic had declarable financial ties with drug companies that were producing antivirals and influenza vaccines. The article claimed that as a result, the WHO was unduly influenced to declare a pandemic and to exaggerate its potential severity, both of which resulted in "billions wasted on a swine flu pandemic that never came."

Whether there is substance to these allegations is being investigated by the WHO pandemic review committee chaired by Dr. Harvey Fineberg, president of the United States (US) Institute of Medicine. As to severity, there is no doubt that the pandemic of 2009 was associated with substantially lower mortality than the 1918 and 1957 pandemics. The case-fatality rate for symptomatic illness was estimated to be $0.05 \%$ in the US $^{9}$ and $0.03 \%$ in the United Kingdom (UK). ${ }^{10}$ By comparison, the case-fatality rate in 1918 was estimated at $1 \%-3 \%$. However, accurately judging the total mortality is difficult. As of June 2010, the worldwide count of deaths caused by laboratory-confirmed pandemic H1N1 influenza was just over $18000 .^{11}$ This count is millions less than that associated with the pandemics of 1918, 1957 and 1968, and substantially less than the estimated number of deaths associated with seasonal influenza epidemics. Because influenza testing is rarely performed, however, global estimates of mortality for historic pandemics and seasonal influenza must be based on statistical attribution of excess all-cause mortality rather than on laboratory-confirmed cases. Even during the

\section{Key points}

- Although the rate of death was lower than had been predicted initially, the numbers of cases of pandemic (H1N1) influenza, of hospitalizations and of years of life lost were substantial.

- Previously recognized at-risk groups suffered most.

- The communication of risk to the public failed.

- Immunization may not be a magic bullet, but it will continue to be an essential component of future preparedness planning for pandemics.

- The pandemic (H1N1) 2009 experience offers important lessons that may help us to prepare for future influenza outbreaks and other emerging infectious diseases.

pandemic of 2009, testing was not readily available in many countries. In other countries, criteria for testing were tightened as laboratories became overwhelmed with requests.

Research published by Viboud and colleagues ${ }^{12}$ suggests that the first waves of the 2009 pandemic may have been more severe than is widely perceived. Using standard methods to estimate deaths caused by influenza during the first and second waves of the 2009 pandemic in the US, the authors estimated the number of deaths from pandemic H1N1 influenza in the US to be between 7500 and 44000 , which is within the same range as the number of deaths caused by seasonal influenza and as the official estimates by the Centre for Disease Control and Prevention. ${ }^{13}$ However, when the authors estimated years of life lost, the numbers were substantially higher. This effect occurred because deaths from the pandemic of 2009 were skewed toward younger ages than deaths from seasonal influenza. During the pandemic, more than three-quarters of cases occurred among people younger than 30 years of age, with a peak among those aged $10-19$ years. ${ }^{14}$ The relative sparing of adults older than 60 years of age was probably a result of previous exposure to viral strains with similarities to the new virus. ${ }^{15}$ The result of this change in epidemiology was that, using the conservative estimate of 7500 deaths, the estimated number of years of life lost was $25 \%$ greater than during a usual influenza season. ${ }^{9}$ If the higher estimate (44 000 deaths) is used, the estimated number of

From Mount Sinai Hospital (Low, McGeer) and the University of Toronto (Low, McGeer), Toronto, Ont.

CMAJ 2010. DOI:10.1503/cmaj.100900 
years of life lost due to pandemic 2009 influenza was three to four times higher than in a virulent $\mathrm{H} 3 \mathrm{~N} 2$ season, five times higher than in seasons with predominant seasonal H1N1 or influenza B viruses, and approximately the same as the number of years of life lost during the 1968 pandemic. All of us should wait to answer the question about whether the pandemic was overhyped until better data are available from around the world on the actual burden of disease attributable to this virus in 2009-2010. Even then, opinions are likely to vary widely.

There was substantial morbidity and mortality, not unexpectedly, in patients with underlying conditions that are associated with complications from seasonal influenza. Pregnant women (especially those in the second or third trimester), women less than two weeks postpartum and patients with immunosuppression or neurologic disorders were overrepresented among those with severe infection with the pandemic H1N1 2009 virus. ${ }^{16-18}$ Although pregnant women represent only $1 \%-2 \%$ of the population, among patients with H1N1 virus infection, they accounted for up to $7 \%-10 \%$ of hospitalized patients, $6 \%-9 \%$ of patients in intensive care units and $6 \%-10 \%$ of patients who died. ${ }^{17}$ Among patients with severe or fatal pandemic H1N1 influenza, severe obesity (body mass index $\geq 35$ ) or morbid obesity (body-mass index $\geq 40$ ) has been reported at rates that are higher by a factor of 5 to 15 than the rate in the general population. ${ }^{17}$

In certain disadvantaged groups, including indigenous populations of North America and the Australasia-Pacific region, rates of severe infection with pandemic $\mathrm{H} 1 \mathrm{~N} 1$ influenza increased by a factor of five to seven. ${ }^{17,18}$ Factors that may have contributed to this trend include crowding, increased prevalence of underlying medical disorders and of alcoholism and smoking, delayed seeking of or access to care, and possibly unidentified genetic factors. Aboriginal status, the presence of coexisting conditions and delayed receipt of antiviral therapy were independently associated with severe disease in a Manitoba study. Aboriginal people accounted for $215(37 \%)$ of the confirmed infections and $65 \%$ of the 45 severe cases in Manitoba. ${ }^{18}$

\section{A massive immunization program}

The Public Health Agency of Canada purchased 50 million doses of pandemic H1N1 influenza vaccine on behalf of the provinces, territories and federal populations, in order to be able to vaccinate every Canadian who wished to be vaccinated. At the time when the contract had to be signed in June, limited data were available on severity of illness. Judging whether a pandemic is severe or not requires distinguishing between case-fatality rates of approximately $1 \%$ and $0.1 \%$ something the best surveillance systems in the world were unable to deliver in the first two months of the pandemic. In addition, it was impossible to judge whether one or two doses of vaccine would be required for protection. Finally, the WHO requested that countries order adjuvant vaccine to maximize the amount of vaccine available for the world.

However reasonable the initial precautionary decision to order 60 million doses of adjuvant vaccine was, subsequent decisions and problems resulted in the wheels falling off the immunization cart. The vaccine could not be made quickly enough to protect Canadians from the second wave, the complexity of delivering vaccine was badly underestimated, and attempts to deliver rapid public education about vaccination with an adjuvant vaccine failed.

Although the standard estimate for vaccine production is six months and the first three million doses of vaccine became available almost six months to the day from initial recognition of the pandemic, it had been hoped that vaccine production would be substantially faster. A brief but valuable period was lost because production of the adjuvant vaccine for H1N1 began only after completion of the seasonal vaccine manufacture. This delay, combined with the fact that the second wave began in October (week 36) meant that substantial supplies of vaccine could not be delivered until the second wave was well under way. ${ }^{19}$

To further complicate the situation, uncertainty and limited communication about vaccine supply hampered local and provincial coordination of delivery. Until week 40, the federal government projected that vaccine would become available in mid-November (week 44). However, during week 40, health units across Canada were told to be ready to start vaccination programs during week 42 . Local health authorities were now charged with getting the vaccine into the arms of Canadians, which was a Herculean task given such short notice and was further complicated by ongoing uncertainties about the weekto-week availability of vaccine. Public health units had two weeks to recruit and train health care workers and to ensure the availability of previously identified sites that could accommodate large clinics and refrigeration trucks to store the vaccine.

To make matters worse, the vaccine was being shipped in 500-dose boxes, substantially complicating local delivery. In Ontario, for example, where family physicians usually provide the great majority of influenza vaccinations, most offices do not require 500 doses of vaccine, resulting in either wastage if they did order it, or compromise of delivery if they did not. The need to mix vials of 10 doses at a time and deliver all 10 within a 24-hour period further complicated administration. Finally, the not-unreasonable desire of the provinces and federal government to track vaccine use (despite the prior almost complete absence of electronic recording of vaccination in public health clinics and physician offices across Canada) created an overwhelming and confusing mass of paperwork.

Logistical issues in vaccine delivery resulted in provinces and local health units making different decisions about vaccine provision. Even recommendations by the Public Health Agency of Canada itself were seen to be confusing, with clear messages about the need to first vaccinate high-priority groups mixed with messages that vaccine would be available to every Canadian who wished it. Because vaccine arrived just before or at peak influenza activity, very rapid delivery of vaccination was the only means of optimizing program impact. In addition, surveys before the vaccination program had suggested that only about $30 \%$ of Canadians were planning to be vaccinated. For this reason, some provinces ini- 
tially attempted to get the vaccine out to as many people and as soon as possible, and did not enforce the priorities of the Public Health Agency of Canada.

These provinces were completely unprepared for the panic that occurred after the highly publicized death from influenza of a previously healthy 13-year-old boy on the night of Oct. 26,2009 - the first day of the vaccination program. Demand for the vaccine almost instantly outstripped the ability of local public health units to supply it. Television broadcasts of long lines of people waiting to be vaccinated contributed to a loss of confidence in the system at a time when public confidence was sorely needed to encourage vaccination. ${ }^{7}$ In addition, because of concern over the safety of the adjuvant vaccine during pregnancy and for children under three years of age, Canada ordered 1.8 million doses of nonadjuvant vaccine from the domestic manufacturer GlaxoSmithKline Inc. This order required the use of one of the manufacturer's production lines to make the adjuvant-free version of the vaccine. The result was that production of the regular pandemic H1N1 vaccine was slowed down, both the limitations of and uncertainty about supply were exacerbated, and additional concern was created about the safety of adjuvant vaccines. By week 48 , vaccination clinics were running more smoothly, but the number of new cases of H1N1 influenza was decreasing. ${ }^{19}$ Unfortunately, most serious infections in the second wave occurred before critical levels of immunity from vaccination could be achieved (Figure 1). ${ }^{20}$

\section{A worried public}

Over the summer and fall, skepticism about the need for the vaccine and its safety began to grow. ${ }^{21}$ An online poll conducted by the Strategic Counsel for The Globe and Mail found that only $49 \%$ of Canadians sampled in October wanted to get the new vaccine, compared with $62 \%$ who had said in a survey conducted in July that they were planning to be vaccinated. In July, the chief medical officer of the National Health Service in the UK, Sir Liam Donaldson, said that the service was planning for almost a third of the population to be struck down by the virus and up to 65000 people to die over the next few months. By the week ending Oct. 25, 2009, only 135 deaths had been attributed to pandemic H1N1 influenza in the UK. In Canada, by the end of week 43, fewer than 100 deaths had been attributed to H1N1.

Safety concerns in Canada were exacerbated by the federal government's decision to use adjuvant vaccine. Although a

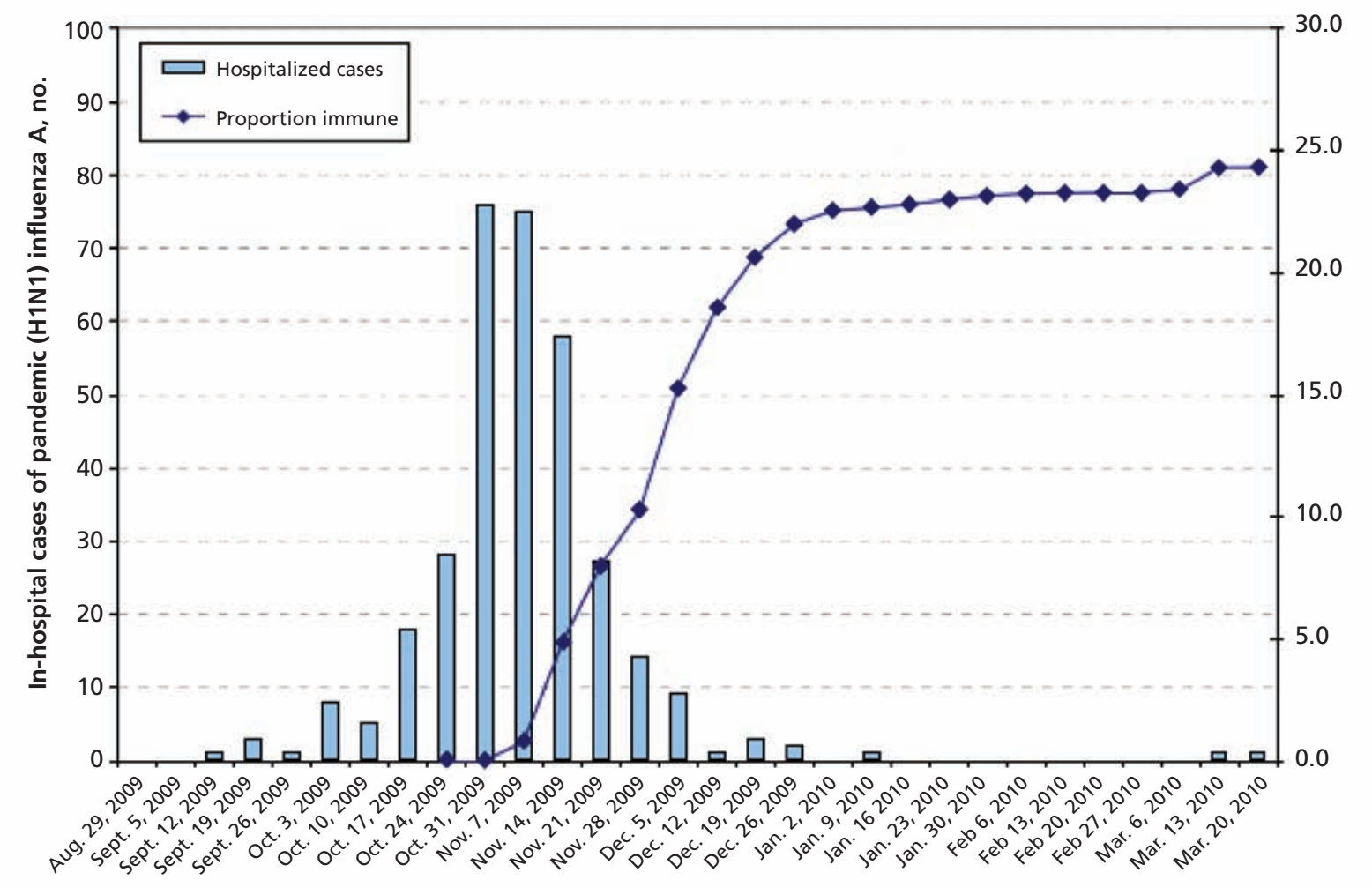

Week exposed*

Figure 1: Weekly reported in-hospital cases of laboratory-confirmed pandemic (H1N1) influenza by date of exposure, shown in relation to the proportion of Toronto residents estimated to be immune to the H1N1 virus because of vaccination. *Date of exposure was estimated by subtracting three days (a typical incubation period for pandemic H1N1 influenza) from the reported date of symptom onset. tThe proportion of residents estimated to be immune because of vaccination was calculated by adding 10 days to the recorded date of vaccination. (Reprinted with permission from Toronto Public Health.) ${ }^{20}$ 
Box 1: Gaps in practice and knowledge related to pandemic influenza

Gaps in practice related to pandemic influenza preparedness in Canada:

- Our federal system of public health, in which knowledge translation and communication is a local responsibility, versus the broad clinical and public perception that communication and knowledge translation should be national ${ }^{6}$

- The existing public health infrastructure versus that recommended by the Naylor Commission ${ }^{26}$

Important questions related to preparing for the next pandemic of influenza:

- Will we be able to deliver vaccine before the second wave of the next influenza pandemic, or is a new approach to vaccination required? ${ }^{8}$

- How can we provide effective public education in the setting of a new disease? Can we better understand the "emotional epidemiology" of pandemic influenza? ?,27,28 $^{2}$

- What is the optimal way to rapidly measure the virulence of a new pandemic influenza virus (i.e., how can we, as quickly as possible, establish narrow confidence limits for case-fatality rates ranging between $0.1 \%$ and $1 \%)$ ?

- What nonpharmaceutical interventions are effective in reducing the spread of influenza, how effective are they and how can they best be implemented?

- Why, in most Canadian studies, did prior seasonal vaccination appear to be associated with an increased risk of symptomatic infection with the H1N1 virus, when this effect was not seen in studies in most other countries? ${ }^{24,25}$

similar adjuvant influenza vaccine had been licensed in Europe since 1997,22,23 adjuvant influenza vaccines had never been used in North America, and the particular adjuvant was not present in any licensed vaccines. Antivaccination groups, advocates for alternative medicine and numerous parents and citizens voiced concern about its safety and claimed that Health Canada was fast-tracking the approval process. ${ }^{24}$ The problem was exacerbated by reports in the media of a Canadian study that found that people who had received the seasonal vaccine were at greater risk for contracting pandemic H1N1 influenza than those who had not been vaccinated. ${ }^{24,25}$ These reports were confusing to the general public and resulted in different and even more confusing provincial decisions about strategies for vaccination against seasonal influenza.

\section{Lessons learned}

The novel influenza A (H1N1) virus emerged in Mexico in March 2009 and spread worldwide within weeks. Although the rate of death was lower than initially predicted, the numbers of cases of H1N1 influenza, of hospitalizations and of years of life lost were substantial. Although the prepandemic investment in planning may have improved our ability to respond to an outbreak, major gaps clearly remain, and the experience of this outbreak raised new questions (Box 1). 6,8,24-28

The majority of pandemic H1N1 influenza vaccine ordered has not, and will not, be used, which may suggest to some that the whole immunization campaign was a waste of taxpayers' money. However, at least some economic analysis suggests that the pandemic vaccination program was actually cost-effective, at an estimated cost of under $\$ 11000$ per quality-adjusted life year. ${ }^{29}$ Most of us also recognize that pandemic vaccine contracts and programs are a form of insurance — not always needed, but still a wise investment.

Despite our best intentions, the vaccination program arrived late, and it failed in some key areas of the country. Whereas Quebec, the Atlantic provinces and the three territories could boast vaccination rates of more than $50 \%$, barely a third of residents in Alberta, Manitoba and Ontario were vaccinated (Figure 2). ${ }^{30}$ Similarly, while Canadian vaccination rates compared favourably with those in the US (about 24\%) and some European countries (both France and Germany vaccinated between $6 \%$ and $10 \%$ of their populations), they remained lower than those of other countries (e.g., Norway, which vaccinated $45 \%$ of its population, and Sweden, which vaccinated $75 \%) .{ }^{8}$ Last year's events clearly show that our current methods of vaccine production are too slow for an adequate response to a pandemic, ${ }^{7}$ that much of our planning for pandemic-related vaccination was incomplete, and that even the best-intentioned program can be undermined by unanticipated internal and external events.

We knew before this pandemic that some populations pregnant women, aboriginal people and those living in relatively closed conditions (e.g., summer camps) — are at particular risk for influenza transmission or severe disease, particularly during pandemics. Despite this knowledge, and despite considerable preparedness efforts across the country, we failed to recognize and address these risks in a timely manner. Protecting the most vulnerable of Canadians is an important social value, and we clearly have room to improve.

As always during outbreaks, communication was the area

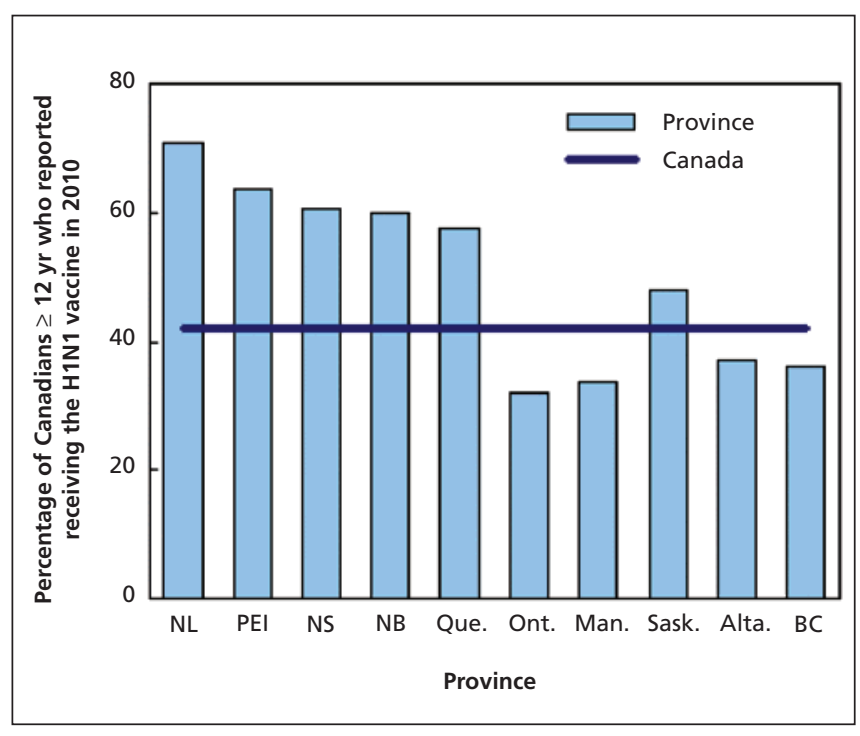

Figure 2: Percentage of the Canadian household population aged 12 years and older who reported receiving the $\mathrm{H} 1 \mathrm{~N} 1$ vaccine, 2010, by province (source: Statistics Canada publication The Daily, 11-001, release date: July 19, 2010) ${ }^{30}$ 
that posed the greatest challenges. A report from the Harvard School of Public Health found that people who didn't get vaccinated didn't believe pandemic H1N1 influenza was dangerous and were also concerned about the safety of the vaccine. ${ }^{27}$ Learning how to deliver the right message to the public and how to educate ourselves about responding to "moderate risk" should be at the top of the list of gaps we need to fill before the next pandemic.

\section{This article has been peer reviewed.}

Competing interests: Donald Low has participated in advisory boards for Roche and Novartis, and has served on speakers bureaus for Roche and GlaxoSmithKline. Allison McGeer has participated in advisory boards for Roche and Novartis. She has served on speakers bureaus for Roche, Biocryst, Sanofi Pasteur and GlaxoSmithKline. She has also received unrestricted investigator grants from Roche and GlaxoSmithKline.

Contributors: Both of the authors contributed substantially to the conception and development of the article, the analysis and interpretation of the data and the drafting and revision of the manuscript. Both of them approved the final version of the manuscript submitted for publication.

\section{REFERENCES}

1. Directorate of Communication. PACE Health Committee denounces "unjustified scare" of Swine Flu, waste of public money [press release]. Strasbourg (France): Council of Europe; 2010

2. Cohen D, Carter P. Conflicts of interest. WHO and the pandemic flu "conspiracies." BMJ 2010;340:c2912.

3. Ontario Ministry of Health and Long-Term Care. Pandemic H1N1. Ottawa (ON) The Ministry; 2010. Available: www.health.gov.on.ca/en/public/publications /ministry_reports/cmoh_h1n1/cmoh_h1n1_20100602.pdf (accessed 2010 Aug. 23).

4. Health and Public Services Committee. Swine flu - the London response. London (UK): Greater London Authority; 2010. Available: www.london.gov.uk/who-runslondon/the-london-assembly/publications/health/swine-flu (accessed 2010 Aug. 23).

5. The Canadian Standards Association. Pandemic H1N1 report. Mississauga (ON): The Association; 2010. Available: www.csa.ca/cm?blobcol=urldata \&blobheader=application $\% 2$ Fpdf \&blobkey=id\&blobtable=MungoBlobs\&blobwhere $=1241708779869 \&$ ssbinary=true (accessed 2010 Aug. 23).

6. Lessons from the front lines: a collaborative report on H1N1. Ottawa (ON): Canadian Medical Association, College of Family Physicians of Canada, and National Specialty Society of Community Medicine; 2010. Available: www.cma.ca /multimedia/CMA/Content_Images/Inside_cma/Media_Release/2010/H1N1-Lessons -from-the-Front en.pdf (accessed 2010 Aug. 23).

7. President's Council of Advisors on Science and Technology (PCAST). Report to the President on reengineering the influenza vaccine production enterprise to meet the challenges of pandemic influenza. Washington: The Council; 2010. Available: www .whitehouse.gov/sites/default/files/microsites/ostp/PCAST-Influenza-VaccinologyReport.pdf (accessed 2010 Aug. 23).

8. Report to the French Senate. La grippe A (H1N1)v: Retours sur la première pandémie du XXIe siècle. Paris (France): Sénat; 2010. Available: www.senat.fr/rap/r09-685-1 /r09-685-1_mono.html (accessed 2010 Aug. 23).

9. Presanis AM, De AD, Hagy A, et al. The severity of pandemic H1N1 influenza in the United States, from April to July 2009: a Bayesian analysis. PLoS Med 2009;6: e1000207.

10. Donaldson LJ, Rutter PD, Ellis BM, et al. Mortality from pandemic A/H1N1 2009 influenza in England: public health surveillance study. BMJ 2009;339:b5213.
11. World Health Organization. Pandemic (H1N1). Geneva: The Organization; 2009 [update 104. 104. 2009]. Available: www.who.int/csr/don/2010_06_11/en /index.html (accessed 2010 Sept. 30).

12. Viboud C, Miller M, Olson D, et al. Preliminary estimates of mortality and years of life lost associated with the $2009 \mathrm{~A} / \mathrm{H} 1 \mathrm{~N} 1$ pandemic in the US and comparison with past influenza seasons. PLoS Curr Influenza 2010;RRN1153.

13. CDC estimates of 2009 HIN1 cases, hospitalizations and deaths in the United States, April 2009-March 13, 2010. Atlanta (GA): Centers for Disease Control and Prevention; 2010. Available: www.cdc.gov/h1n1flu/estimates_2009_h1n1.htm \#Table\%20Cumulative (accessed 2010 Aug. 23).

14. Reichert T, Chowell G, Nishiura H, et al. Does glycosylation as a modifier of original antigenic sin explain the case age distribution and unusual toxicity in pandemic novel H1N1 influenza? BMC Infect Dis 2010;10:5.

15. Miller E, Hoschler K, Hardelid P, et al. Incidence of 2009 pandemic influenza A H1N1 infection in England: a cross-sectional serological study. Lancet 2010; 375:1100-8

16. Louie JK, Acosta M, Jamieson DJ, et al. Severe 2009 H1N1 influenza in pregnant and postpartum women in California. N Engl J Med 2010;362:27-35.

17. Writing Committee of the WHO Consultation on Clinical Aspects of Pandemic. (H1N1) 2009 Influenza. Clinical Aspects of Pandemic 2009 Influenza A (H1N1) Virus Infection. N Engl J Med 2010;362:1708-19.

18. Zarychanski R, Stuart TL, Kumar A, et al. Correlates of severe disease in patients with 2009 pandemic influenza (H1N1) virus infection. CMAJ 2010;182:257-64.

19. Public Health Agency of Canada. Summary of FluWatch findings for the week ending January 16, 2010. Ottawa (ON): The Agency; 2010. Available: www.phacaspc.gc.ca/fluwatch/09-10/w02_10/index-eng.php (accessed 2010 Mar. 15)

20. 2009-2010 pH1N1: Influenza pandemic summary report. Toronto (ON): Toronto Public Health; 2010. p. 1-25. Available: www.toronto.ca/legdocs $/ \mathrm{mmis} / 2010 / \mathrm{hl}$ /bgrd/backgroundfile-30493.pdf (accessed 2010 June 15)

21. Schafer A, Cassels A. What do we know about the vaccines' safety? Not enough The Globe and Mail 2009 Aug 5. Available: www.theglobeandmail.com/news /opinions/what-do-we-know-about-the-vaccines-safety-not-enough/article1242422/ (accessed 2010 Aug. 23).

22. Vesikari T, Pellegrini M, Karvonen A, et al. Enhanced immunogenicity of seasonal influenza vaccines in young children using MF59 adjuvant. Pediatr Infect Dis J 2009;28:563-71.

23. Durando P, Icardi G, Ansaldi F. MF59-adjuvanted vaccine: a safe and useful too to enhance and broaden protection against seasonal influenza viruses in subjects at risk. Expert Opin Biol Ther 2010;10:639-51.

24. Skowronski DM, De SG, Crowcroft NS, et al. Association between the 2008-09 seasonal influenza vaccine and pandemic H1N1 illness during Spring-Summer 2009: four observational studies from Canada. PLoS Med 2010;7:e1000258.

25. Viboud C, Simonsen L. Does seasonal influenza vaccination increase the risk of illness with the 2009 A/H1N1 pandemic virus? PLoS Med 2010;7:e1000259.

26. National Advisory Committee on SARS and Public Health October 2003. Learning from SARS - renewal of public health in Canada. Ottawa (ON): Public Health Agency of Canada. Available: www.phac-aspc.gc.ca/publicat/sars-sras/naylor/ (accessed 2010 Aug. 23).

27. Steelfisher GK, Blendon RJ, Bekheit MM, et al. The public's response to the 2009 H1N1 influenza pandemic. N Engl J Med 2010;362:e65.

28. Ofri D. The emotional epidemiology of H1N1 influenza vaccination. N Engl J Med 2009;261:2594-5.

29. Sander B, Bauch CT, Fisman D, et al. Is a mass immunization program for pandemic (H1N1) 2009 good value for money? Evidence from the Canadian experience. Vaccine 2010;28:6210-20

30. Canadian community health survey. HINI vaccinations. Ottawa $(\mathrm{ON})$ : Statistics Canada, The Daily; July 19, 2010. Available: www.statcan.gc.ca/daily-quotidien /100719/dq100719b-eng.htm (accessed 2010 Sept. 28)

Correspondence to: Dr. Donald Low, Department of Microbiology, Mount Sinai Hospital, 600 University Ave., Rm. 1487, Toronto ON M5G 1X5; dlow@mtsinai.on.ca. 